\title{
The future of mega sport events: examining the "Dutch Approach" to legacy planning
}

\author{
Stefan Hartman and Tjeerd Zandberg
}

\author{
Stefan Hartman is a \\ Researcher in Spatial Planning \\ and Tourism Development and \\ Tjeerd Zandberg is a \\ Researcher in Economics and \\ Scenario Planning, both based \\ at the European Tourism \\ Futures Institute, Leeuwarden, \\ The Netherlands.
}

\begin{abstract}
Purpose - Mega sport events (MSE) are immensely popular but also highly criticized because these include large public budgets and involve politically sensitive topics. In this context, there is an increasing attention toward legacy planning, the effort to confer long-term benefits to a host destination through organizing MSEs, such as the Olympic Games. When it comes to event planning, large-scale master plans are a common approach. However, in the Netherlands the authors see that an alternative development model is pursued called the Dutch Approach to prepare for the possible candidature to host the Olympic Games of 2028. This paper aims to analyze this approach with a specific focus on whether this approach has the potential to result in a positive legacy.
\end{abstract}

Design/methodology/approach - The research involves a literature review which distinguishes factors that positively or negatively influence event legacies. This results in a framework which is used as a guide for a content analysis of data on the Dutch Approach. Hence, data are obtained from analyzing academic and professional literature, policy documents, research reports, and newspaper articles on the Dutch Olympic ambitions, and the planning approach thereof. Moreover, data are derived from a study by the authors on the development of the area "Sportas Amsterdam".

Findings - The research identifies factors that can contribute positively and negatively to the legacy of events. It provides a unique insight into the planning process of The Netherlands in the context preparing a bid for the Olympic Games of 2028. What can be learned from the Dutch Approach is that planning for a positive legacy is a long-term and complex process that heavily relies on the support of a range of stakeholders. Due to the range of actors involved, it involves much negotiations and becomes increasingly difficult to achieve consensus.

Research limitations/implications - The paper provides a reflection on the concepts of legacy and legacy planning, and outlines a set of propositions concerning the future of MSEs that present an agenda for further research. By doing to, the paper highlights the importance of focusing on how the relations between stakeholder involvement, planning approaches, and types of urban regimes influence the extent to which a positive legacy can be achieved.

Originality/value - The paper provides a state of the art overview of contributions on event legacy and legacy planning. It draws attention to conditions for positive legacies and implications for planning and governance approaches. It is argued that a top-down government-led approach to a MSE will probably have less impact on future tourism compares to the Dutch Approach.

Keywords Planning, Futures, Legacy, Mega sport event, Olympic

Paper type Research paper

\section{Introduction}

There is always a fierce competition between cities or regions to organize mega sports events (MSEs) such as the Olympic Games or World Soccer Championships. There seems to be a kind of magic around these events which makes people believe these are worthwhile to organize. Benefits include place marketing (Matheson, 2010), global audiences and massive television 
revenues for host destinations (Whitson et al., 2006), urban regeneration, infrastructure improvement, (Smith, 2014), strengthening international relations, employment opportunities, and sports participation. Moreover, MSEs attract huge numbers of visitors during the event such as athletes, support staff, officials, press, spectators whereas the heritage consisting of buildings, performances, memories, and museums also attract visitors (long) after the event to host destinations (Gibson et al., 1998). Legacy planning is therefore of direct relevance for tourism futures.

MSEs are, however, also criticized for various reasons. According to Whitson et al. (2006) the events are often organized as special projects of political and business elites. Infamous are the so-called "white elephants", the abandoned sports facilities that remain unused after the event. MSEs involve often huge (public) investment, which may result in debts. The debt of the Montreal 1976 Olympic Games in was 1.5\$ billion. It took until 2008 to pay off what became known as the "Big Owe". It is also doubtful if the 40 billion euro investment in Sochi will ever be paid back. Besides, deterioration of natural, cultural, historical resources can be consequences of building activities. Urban restructuring is often needed to provide the physical space for infrastructure and sports facilities. This can result in displacement of original inhabitant and the gentrification of communities. The emphasis on economic and political benefits may exceed a focus on local communities and their development. Furthermore, specialised development agencies may distance local communities and authorities from decision making, resulting in outcomes that may not necessarily be supported by a range of stakeholders.

Clearly, events can have an impact on a host destination before, during, and after an event. This is known as a "legacy". The legacy of an event can be defined as the "planned and unplanned, positive and negative, tangible and intangible structures created for and by a sport event that remain longer than the event itself" (Preuss, 2007, p. 211). In this paper we examine factors that are important when aiming to plan for a positive legacy. The first part of the paper concerns a literature study. This is done to identify factors that are related to negative legacy which need to be avoided and factors that contribute to a positive legacy which need to be emphasized. The second part of the paper elaborates on the "Dutch Approach" (see De Groot et al., 2012) to the planning of MSEs. The Dutch Approach is explained with a reference to the process of preparing a bid for the 2028 Olympic Games. By doing so, a unique insight is provided into the process and emerging issues that relate to generating a positive legacy. Finally, we combine the insights presented in this paper to formulate a set of propositions concerning the future planning of MSE and managing their contributions to tourism. The specific contribution of this paper to the literature on legacies of MSEs and impacts of MSEs on tourism comes with the analysis of the Dutch Approach, being as a method of legacy planning that has the potential to positively influence future tourism development.

\section{Theoretical perspectives on legacies: a multifaceted and contested concept}

Legacy is used as a term to refer to the impact before, during, and after an event on a host destination. Legacies can be classified in different ways. Preuss (2007), for instance, identifies six elements: infrastructure, know-how, networks, culture, emotions, and image. Moreover, Chappelet (2012) points out that legacies may be planned and top-down implemented such as enhanced infrastructure and mobility. Legacies could also be unplanned and emerge from the bottom-up, such as positive and negative emotions towards an event and its impacts. Over the last decade, attention for the legacy of events has grown substantially. For the International Olympic Committee (IOC) the ex-ante evaluation of the expected legacy has become a major element in bid procedures. Simultaneously, there is an emerging body of literature on legacy planning and management (Ritchie, 2000; Cashman and Horne, 2013; Mangan and Dyreson, 2013; Smith, 2014; Scott, 2014).

Despite the problems involved in organizing MSEs, the strong competition between cities that are interested to organize them is an indication that many cities consider MSEs attractive to organize. The winners of these competitive processes are determined by powerful international sports organizations. This selection process is formalized in a so-called bid process in which prospective organizers describe their plans. The nature of this process encourages a strong 
emphasis on both an effective lobby process as well as formal planning including the legacy planning (International Olympic Committee (IOC), 2013). In this context, Chappelet (2012, p. 80) wonders about whose legacy one is talking about: "that of the local population, that of the urban regime i.e. the political and economic leaders of the host region (including the organizing committee), and that of the owner of the event (who attributed it to the city)" such as the OIC or the FIFA?

The literature review brings us to the conclusion that legacies are likely to be multifaceted and views on legacies contested (Whitson et al., 2006). Multifaceted because benefits could range from political, infrastructural, temporal to place specific. Some facilities may be used for decades after an event whilst others become forgotten almost instantaneously. Compare to Beijing where the Olympic swimming pool is converted to a recreational pool and sports complexes for table tennis are enhanced, whilst facilities for kayaking, beach volleyball, and baseball have been abandoned and are in an advanced state of disrepair. Contested because events may also be a success from political or macro-economic perspectives, whilst on a local societal level people suffer from displacement or gentrification. The long-term influence on tourism is therefore also likely to vary. Barcelona is an example of how the Olympic Games are used to brand the city as a major destination for short breaks, whilst Athens has not been able to rebrand itself by means of the Olympic Games.

Against this background we dive in the literature on legacy planning to provide an enhanced understanding of the relations between planning processes and event legacies. The purpose of doing so is to draw attention to factors in planning processes that have a capacity to contribute to a more positive and lasting effect. Methodologically, we executed a structured content analysis of academic literature and reports. Literature on event planning, legacy planning, and impact studies of mega events were reviewed and coded as such to distinguish aspects of legacy planning that authors attribute to a positive legacy (critical success factors) and factors that are related to a negative legacy (failure factors). By doing so, we are able to discuss the relationships between legacies and planning strategies, and distinguish factors that may productively contribute to more positive legacies. These insights are used to discuss the Dutch Approach, whereby we elaborate on whether the Dutch Approach has the potential to serve as a sustainable development model when it comes to legacy planning. Data on the Dutch Approach are obtained from analyzing academic and professional literature, policy documents, research reports, and newspaper articles on the Dutch Olympic ambitions, and the planning approach thereof. Partly, data are derived from a study by the authors on the development of the area that is framed as "Sportas Amsterdam".

\section{Planning for positive legacies}

The increasing attention towards the idea of generating a positive legacy served as a trigger for the emerging field of legacy planning. Legacy planning is defined as planning for long-term benefits to host destinations (Ritchie, 2000). As discussed, on the basis of a literature review the following aspects of legacy planning were identified that authors attribute to a positive legacy (critical success factors) and factors that are related to a negative legacy (failure factors).

\section{Factors contributing to a positive legacy}

All factors relate to starting well in advance to think about, and plan for, a range of impacts of the event and the development phase thereof (Sadd and Jones, 2009; Matheson, 2010; Taylor and Edmondson, 2007). A frequently highlighted aspect is developing a long-term perspective, whereby an event is embedded in a larger pre-and post-event development programme. For instance, organizing side events prior, during, and after the main mega event (Ritchie, 2000). Alternatively, an event can be used as a catalyst to encourage youth to participate in sports, for urban redevelopment, or to enhance infrastructure (Ritchie, 2000; Sadd and Jones, 2009). These aspects implicitly articulate the need for a focus that goes beyond economic and infrastructural factors, and includes social, community, and education objectives (Smith, 2014). Post-event planning includes keeping the memory of an event alive, through a legacy foundation, online spaces, and on-site referrals (Chappelet, 2012).

PAGE 110 | JOURNAL OF TOURISM FUTURES $\mid$ VOL. 1 NO. 22015 
Furthermore, the multifunctional use of investments in infrastructure, mobility, transportation, and public space are stressed. This is not about creating a separate park within a city, but framed as creating an urban park that is integrated in the urban fabric (Kotzen and Güller, 2012). Related to integrating facilities into the urban fabric are the use existing sports facilities. This was a major contributor to the net profit of the Los Angeles 1984 Olympic Games (Chappelet, 2012). It also relates to planning for the future (re)use of facilities and locations (Ritchie, 2000). Additionally, possible strategies are legacy funds, designing for facilities that can be downscaled or converted (Chappelet, 2012), using temporary facilities (Smith, 2014), and to involve parties that have a stake in the future operation of facilities and locations in contrast to footloose ones that leave when the event is over (Taylor and Edmondson, 2007).

In terms of governance and decision making, several points are raised in the literature. First, clear governance rules and accountability are important, which often includes establishing development cooperations. Smith (2014) argues, though, that these may potentially distance the local electorate from decision making. Second, robust partnerships are emphasized (Kissoudi, 2008). For example, a "legacy cooperation" that is responsible for, and have the capacities to, ensuring that factors that negatively influence a legacy are avoided or mitigated, and positive factors are stimulated during the planning process. Examples are the "Legacy Barbados Inc." for the 2007 World Cricket Cup, the "2010 Legacies Now Society" for the Vancouver 2010 Winter Olympics and the "London Legacy Development Cooperation" for the London 2010 Olympic Games. Another option is a sports networking organization that matches local companies with potential overseas clients and customers at major sporting events (Taylor and Edmondson, 2007). Moreover, taking a cyclic, adaptive planning strategy to revisit taken approach is considered to be an important factor, in case it become evident during a planning process that the legacy of an event is becoming contested or that improvements can be made (Sadd and Jones, 2009).

\section{Factors contributing to a negative legacy}

The planning factors that are related to a negative legacy highlight that hosting an event is often coupled to a selective focus or that little attention is paid to long-term effects. First, as Smith (2014, p. 4) states: "planning the post-event transformation of these spaces is something that has normally happened in a rather ad hoc and retrospective manner". Second, events are portrayed as uncoordinated acts of imagineering and practices of branding geared towards economic or political gain, that overlook local communities and processes of placemaking (Rutheiser, 1996). In many examples of the past, the planning and development process involved large (public) investments, at the expense of taxpayers (Chappelet, 2012; Sadd and Jones, 2009) and other public investments in society. This could be the case when specialist event agencies are introduced, that distance local communities and authorities from decision making. Moreover, time pressure decreases the likelihood of community involvement (Smith, 2014). Third, development could be accompanied by various externalities. Infamous are the white elephants, the obsolete venues due to inadequate utilization and legacy planning (Matheson, 2010). Urban restructuring, for its part, be result in an act of gentrification. People may be displaced when they are forced to relocate, which potentially involve relocating issues to other parts of a city (Malfas et al., 2004; Smith, 2014). In addition, a selective focus may result in the deterioration of cultural, historical, and natural resources

The success and failure factors of legacy planning will be used in the following section to analyze the planning approach taken in the Netherlands in preparation of a possible bid for the Olympics of 2028. This allows us to comment on whether the planning approach taken in the Netherland has the potential to result in a positive, long-term legacy.

\section{Learning from the Dutch Approach}

Due to the changing norms and values to today's society, organizing MSEs and planning for positive legacies in the context of consensus oriented, egalitarian regimes becomes increasingly difficult. Even though the organization of the London 2012 Olympic Games spent more attention to legacy planning compared to any destination in the past (Thornley, 2012), the public 
investment of $£ 9$ billion is still criticized (see Smith, 2014). Moreover, it is also reflected by Norway pulling out of the bidding procedure for the 2022 Winter Olympics. Reasons included huge public investments, unclear return on investment, as well as disputable demands by the event owners. Referendums in Switzerland and in the German region of Bavaria also proved that there was no interest in hosting the Winter Olympics of 2022. Host destinations that remain interested in organizing MSEs are the more authoritarian regimes. These have the financial resources and political capabilities to host mega events. However, these regimes often pursue a top-down, blueprint planning approach. Examples are the Beijing 2008 Olympic Games, the Sochi 2014 Winter Olympics, and the Qatar 2022 World Soccer Championships. It is debatable whether the size and scale of these events fit local contexts and whether the sites and facilities can be sustainably supported by the (local) society.

In the Netherlands, however, an alternative "Dutch Approach" to legacy planning of MSEs can be observed in the context of preparing a bid for the 2028 Olympic Games. Preparations have started already in 2006 even though expressing candidature and submitting a bid for the Olympics in 2028 is officially due in 2019. The Dutch Approach is characterised on the one hand by a focus on creating a positive legacy and on the other hand by a focus on establishing consensus and support amongst a wide variety of stakeholders. The Dutch Approach to the case of the 2028 Olympic Games is discussed in more detail below.

First, in 2006 the NOC*NSF - the Dutch Olympic Committee and National Sports Federation - drafted the "Olympic Plan 2028" to explore the possibilities to organize the Games and articulate the ambitions and strategies to achieve the ambitions. The ambition is determined as using the Games as a catalyst to enhance professional sports environment, stimulate recreational sports and participation, to stimulate socio-cultural, economic, spatial development and wellbeing, articulate the ability to organize events and to garner media attention (NOC*NSF, 2009). The emphasis on societal development is also explained because of the importance to find a "balance between large-scale investments and the preservation of public support" (Cohen de Lara and Mulder, 2012, p. 34). Striking is that the event is not seen an end, but a means for development. Moreover, the intention is to achieve as much of the ambitions in the period prior to the Games. As such, Ovink (2012) argues the Olympic Plan is not a project but a process: it "does not end with the Olympics themselves but long afterwards. Nor did it begin after the bid was won but was under way long before that. The Games are a strategic moment, a catalyst for the entire process targeted at delivering the stated broad Olympic ambitions" (pp. 4-5). Hornis (2012) adds that "the 2028 Olympics are a cherry on the cake - even if nothing comes of them, the 'Olympic ambition' will already have made its mark" (p. 6).

Second, the Ministry of Infrastructure and Environment (I\&M) is defining the "Olympische Hoofdstructuur" (Olympic Main Structure), a strategic spatial planning approach that includes all developments necessary to host the Games. This plan spends much effort on realizing a positive legacy. Investments are spread over a larger area, as Amsterdam will be the host city and Rotterdam partner city. Possibilities are explored for temporary buildings (apartments, media centre) and temporarily up scaling sports facilities through innovative constructional solutions - thereby simultaneously stimulating "Dutch Design" and creating an export product. A "route map" is proposed to embed the Games in a sequence of events. It is also argued that many actors should be involved in the planning process, for instance to ensure that facilities are supported by society and do not turn into "white elephants". The assumption is that the more society is involved in the preparation process, the more inclusive the approach becomes, and the more it can become their Games.

Third, the city of Amsterdam and its partners are transforming a zone with fragmented sports facilities into a high-quality leisure-oriented sports landscape. This project is referred to as the Sportas. The Sportas project concerns the development of an area in between the city centre of Amsterdam and Amsterdam Schiphol Airport. The area features the 1928 Olympic stadium, rowing facilities, a tennis stadium, a cricket ground, and a hockey stadium. The Sportas is already used for hosting (pre-Games) events such as the Dutch Championships for speed skating, the European Athletics Championships (hosted in 2016) and the World Rowing Championships in 2014. The approach chosen by the city of Amsterdam to develop this area is

PAGE 112 | JOURNAL OF TOURISM FUTURES | VOL. 1 NO. 22015 
focusing on several elements. Of course the first goal is to create high-quality sport facilities to support Dutch top-sport ambitions. This is done by bringing together sports people from different disciplines in one area, to facilitate the contacts and exchange of ideas between different sport disciplines. A second objective is to use sports as a mean to further development Amsterdam an attractive city for the 18-35 year population. In the area of the Sportas this is done by combining investments to enhance culture, nature, recreation, leisure, sport, tourism, architecture, public space, safety, and to foster local sports associations. In doing so, the city of Amsterdam involves the society in developing their plans. As such, there is a combination of top-down planning and bottom-up efforts. Top-down interventions relate to public authorities providing funding and taking the lead in the organization, amongst others by establishing a project agency that is responsible for executing a multiannual development programme. Bottum-up input relates to the involvement of local entrepreneurs and societal organizations. This combination is referred to as "co-creation" in Dutch planning practice. The Sportas project is an example of how more local scale initiatives can contribute to the large-scale Olympic Plan, e.g. involving a range of stakeholders to upgrade the area and its facilities and acting as a decor for events that contribute to the "route map" of events that may lead up to the Games.

On the basis of the above, Table I provides an overview for the Dutch Approach to event planning that is discussed above. It shows how positive factors are included and how negative factors are avoided or mitigated.

Whereas in the Dutch Approach there are many aspects that relate to generating a positive legacy, various issues emerged that proved to be counterproductive for organizing the Olympics (Olympisch Vuur, 2013). There were discussions about the intentions of the Olympic Plan: is it about organizing the Games or about brining Dutch athletes to the Olympic level? Is the specifically initiated programme office a catalyst with partner stakeholders (cities, provinces, state, societal partners) as implementers, or should they initiate and execute projects

Table I The Dutch Approach to event planning in relation to a positive legacies

How positive factors are included

Organizing pre-events

Events are already organized, for example the National speedskating championship in 2014 or European Athletic championship in 2016, yearly marathons, rowing championships

Multifunctional infrastructure Hotels are used for sports and non-sports visitors, such as tourists. Citizens can use the area for recreation and leisure. Festivals are already organized on the area. Sports facilities are embedded in society, and if purpose built for an event it is temporal, can be reused or relocated

Cooperation with stakeholders in society Many local actors are involved in various projects that contribute to the overall Olympic ambition. Dutch companies and professionals are involved in the planning process, also aimed at creating exportable product and services
How negative factors are avoided or mitigated

Ad hoc planning

The planning process is not ad hoc, but phased, long term which much attention to pre-Games and post-Games situations

Uncoordinated planning

Planning is not uncoordinated; it is driven by the overall Olympic Plan 2028. The ministry of I\&M monitors and takes a coordinative role. At the more regional and local-level actors also engage in planning processes, such as the Sportas project by the city of Amsterdam and its partners

Distance between planning and community Planning actors try to keep the distance as little as possible. Involving communities and stimulating community driven development is key to the planning approach. Nevertheless, distance may occur due to formal decision-making processes and procedures

Time pressure

To avoid time pressure, phases of consensus building and design were started long before engaging in the official bid procedure

Undesirable externalities

Much effort is put to avoid externalities, amongst others stating an extensive and inclusive planning process long before the event, even before engaging in the bidding procedure 
themselves? Moreover, a societal resistance emerged to conform to the policies and regulation of organizations that own the events. Also a resistance emerged, being triggered by an official cost-benefit analysis, towards the large public investments needed for organizing the 2028 Olympics Games. Finally, a change of the house of Representative meant a decrease of political support and resulted in the decision not to provide public funds.

What can be learnt from the Dutch Approach is that planning for a positive legacy is a long-term and complex process. It relies heavily on the support of a range of stakeholders. This is hard to organize and involves much negotiations. Due to the range of actors involved, it becomes increasingly difficult to achieve consensus. Furthermore, clarity is needed about who is responsible, whether stakeholders can be held accountable, and who as the mandate to made decisions. The urban regime of a host destination must also be open to this type of approach, which is dependent on political traditions, the planning culture, and economic stakeholders. Hence, as planning for a positive legacy relates to the involvement and influence of society (civilians, firms, organizations, and other stakeholders), it comes with conditions regarding the planning approach and with implications for the urban regime.

\section{Conclusions and discussion}

In The Netherlands, much attention is paid to legacy planning. Whereas this is required by the IOC, it also fit Dutch culture to critically assess development plans that involve public investments. The approach taken is long term, consist of multiple phases and aims to achieve results long before the actual Games are organized, e.g. by involving as many stakeholders as possible and using community input. The idea is to embed the event as much as possible in the Dutch society, making it a community-driven and community-oriented development project. The necessary facilities are located inside the city and developed by distinct stakeholders before the Olympic Games are actually taking place. Hence, the Dutch planning strategy to prepare for the 2028 Olympics Games draws attention to several factors that can contribute to a sustainable development model for a positive legacy. A key aspect of the approach it that organizing the Olympic Games is not seen as the end goal that has to be reached, but seen as the ultimate reward for a long term, community-driven planning and development approach. The event is not seen an end, but a means for development. As such, the research indicates that several basic conditions for a positive legacy are being met. It is argued that the Dutch Approach already garnered results in the planning phase, particularly concerning the enhanced connectivity of stakeholders, improved organizing capacity, and more know-how about the process of organizing MSEs (Olympisch Vuur, 2013). A major condition is, however, that actors keep investing in organizing capacity. Attention needs to be paid to gaining public support, to organizing side events, connecting the events to networks of sports organization, institutions and businesses in and outside the Netherlands. Without actors being able and willing to invest in the comprehensive, inclusive and therefore complex planning process hosting a MSE such as the Olympic Games in The Netherlands will become very problematic.

On the basis of our findings in literature and conclusions regarding the Dutch Approach we coin a set of propositions that can be seen as an agenda for further research. We believe that event legacies can and will be perceived differently by different stakeholders. The propositions therefore address questions related to legacy for whom? Each proposition is designed with the aim to better understand important conditions and (political) choices that are needed to achieve a positive legacy for a particular group of stakeholders:

\section{P1. A positive legacy for society benefits from an inclusive planning approach.}

This proposition departs from the understanding that achieving a positive legacy for society requires an extensive process wherein societal partners are included in the preparation and design phase of the event. This requires a more horizontal approach to planning and governance. The consequence is that it might involve a complex, difficult, and lengthy negotiation process amongst many stakeholders on different governance levels. Amongst the conditions is therefore the ability and willingness to engage in such a long-term process and open up for processes of co-creation. Hence, it could be a conclusion that this is more likely to

PAGE 114 | JOURNAL OF TOURISM FUTURES | VOL. 1 NO. 22015 
achieve in countries where the importance of consensus and societal participation in decision-making is embedded in the culture and politics of destinations:

P2. A positive legacy for the event owner benefits from a top-down government-led planning approach.

This proposition departs from the perspective that one of the most important factors for event owners is that the events itself is a success. It requires host destinations that are willing and able to provide the resources for a well-organised event. Guaranteeing that event preparations will be finished on time, have a high-quality standard to support the performances of athletes, and result in a unique experience for the audience requires sufficient resources. For these purposes, top-down government interventions may ease such processes, as is shown by the recent cases of the Sochi 2014 Winter Olympics and the Qatar 2022 World Soccer Championship:

P3. A positive legacy for future tourism benefits from a Dutch Approach.

A key element in the Dutch Approach is that it connects many stakeholders in the preparation of an event. It ensures that the event is embedded in a broad setting, involving infrastructure, sports and business networks, and destination marketing. These factors make it more likely that organizing a MSE in this manner will contribute to future tourism development:

P4. A positive legacy for all stakeholders will never completely achieved.

This proposition departs from the position that meeting all the conditions that are needed for creating a positive legacy for all stakeholders is likely to be unrealistic. This requires a very long and comprehensive process, and will therefore come with huge pressures on budgets, commitments and organizing capacities. Potentially, not all conditions can be met. The position is taken that event legacies will therefore always accompany some negative effects for particular stakeholders groups whilst the overall perception can still be very positive.

Addressing these propositions has the potential to lead to a better understanding of the conditions that are needed to achieve a positive legacy. Potentially, when organizing MSEs not all conditions can be met (P4). Choices must then be made. In this context it is useful to have insight into the relations between event legacies and conditions to achieve these legacies in terms of planning and governance approaches. Subsequently, it is important to assess whether these conditions can be met given the political, financial, and socio-cultural context of the host destination. Further research on these issues can enhance our understanding of event legacies and legacy planning of MSEs.

\section{References}

Cashman, R. and Horne, J. (2013), “Legacy management”, in Frawley, S. and Adair, D. (Eds), Managing the Olympics, Palgrave Macmillan, Houndmills, pp. 50-65.

Chappelet, J. (2012), "Mega sporting event legacies: a multifaceted concept”, Papeles de Europa, Vol. 25, pp. 76-86.

Cohen de Lara, M. and Mulder, D. (2012), "The Netherlands as game changer", in De Groot, D., Hornis, W. and Wierenga, E. (Eds), Designing Olympics, 010 Publishers, Rotterdam, pp. 30-41.

De Groot, D., Hornis, W. and Wierenga, E. (2012), Olympisch Ontwerpen: Designing Olympics, 010 publishers, Rotterdam.

Gibson, H.J., Attle, S.P. and Yiannakis, A. (1998), "Segmenting the active sport tourist market: a life-span perspective", Journal of Vacation Marketing, Vol. 4 No. 1, pp. 52-64.

Hornis, W. (2012), "Inleiding”, in De Groot, D., Hornis, W. and Wierenga, E. (Eds), Designing Olympics, 010 Publishers, Rotterdam, pp. 6-9.

International Olympic Committee (2013), Olympic Legacy, IOC, Lausanne.

Kissoudi, P. (2008), "The Athens Olympics: optimistic legacies - post-Olympic assets and the struggle for their realization”, The International Journal of the History of Sport, Vol. 25 No. 14, pp. 1972-90.

VOL. 1 NO. 22015 | JOURNAL OF TOURISM FUTURES | PAGE 115 
Kotzen, B. and Güller, G. (2012), "Vergeten reis, vergeten verleden”, S\&RO, Vol. 93 No. 1, pp. 23-7.

Malfas, M., Theodoraki, E. and Houlihan, B. (2004), "Impacts of the Olympic Games as mega events", Municipal Engineer, Vol. 157 No. 3, pp. 209-20.

Mangan, J.A. and Dyreson, M. (2013), Olympic Legacies: Intended and Unintended: Political, Cultural, Economic, and Educational, Routledge, Abingdon.

Matheson, C.M. (2010), "Legacy planning, regeneration and events: the Glasgow 2014 Commonwealth Games", Local Economy, Vol. 25 No. 1, pp. 10-23.

NOC*NSF (2009), Olympisch Plan 2028, Em. de Jong, Baarle-Nassau.

Olympisch Vuur (2013), Legacy 2028, Arko Sports Media, Nieuwegein.

Ovink, H. (2012), "Tangibly Olympic", in De Groot, D., Hornis, W. and Wierenga, E. (Eds), Designing Olympics, 010 Publishers, Rotterdam, pp. 4-5.

Preuss, H. (2007), "The conceptualisation and measurement of mega sport event legacies", Journal of Sport \& Tourism, Vol. 12 Nos 3-4, pp. 207-28.

Ritchie, J.R.B. (2000s), "Turning 16 days into 16 years through Olympic legacies”, Event Management, Vol. 6 No. 3, pp. 155-65.

Rutheiser, C. (1996), Imagineering Atlanta: The Politics of Place in the City of Dreams, Verso Books, London.

Sadd, D. and Jones, I. (2009), "Long-term legacy implications for Olympic games", in Raj, R. and Musgrave, J. (Eds), Event Management and Sustainability, CAB International, Wellingford, pp. 90-8.

Scott, C. (2014), "Legacy evaluation and London, 2012 and the Cultural Olympiad", Cultural Trends, Vol. 23 No. 1, pp. 7-17.

Smith, A. (2014), “'De-Risking’ East London: Olympic regeneration planning 2000-2012”, European Planning Studies, Vol. 22 No. 9, pp. 1919-39.

Taylor, M. and Edmondson, I. (2007), "Major sporting events - planning for legacy", Municipal Engineer, Vol. 160 No. 4, pp. 171-6.

Thornley, A. (2012), "The 2012 London Olympics. What legacy?”, Journal of Policy Research in Tourism, Leisure and Events, Vol. 4 No. 2, pp. 206-10.

Whitson, D., Horne, J. and Manzenreiter, W. (2006), "Underestimated costs and overestimated benefits? Comparing the outcomes of sports mega-events in Canada and Japan", Sociological Review, Vol. 54 No. 2, pp. 71-89.

\section{Corresponding author}

Stefan Hartman can be contacted at: stefan.hartman@stenden.com 